\title{
Announcement
}

\section{International Register of Computer Projects in Systematics}

\author{
Sponsored By:
}

The International Association For Plant Taxonomy, and The Society of Systematic Zoology

\section{CALL FOR INFORMATION ON PROJECTS, PROGRAMS, AND DATA FILES}

The two above-mentioned international associations are the prime sponsors of an International Register of Computer Projects In Systematics. For the purpose of the Register, systematics includes taxonomy, biosystematics, evolution, and biogeography of all biological taxa. The Register also welcomes information about nonbiological data files of use to systematics (e.g., the long-range weather data tapes of the U.S. Weather Bureau). For the present, our project is a Register that hopefully can direct people to the source of information desired. Depending on demand, it could be extended into a repository and clearing house for computerized files of systematic value.

As in the first such Register (see Taxon 19:63-76, 1970 ), we welcome systematic information on computerized data files about living organisms, preserved organisms, experimental data, literature files, etc. We also welcome information on wellwritten and documented computer program packages (other than basic statistics) that are of value for systematic research and/or teaching.

If you or a colleague uses computers in systematics (or definitely plan to), please write to the Chairman of the Register and request as many copies of the Register Questionnaire as you have separate projects or program packages. You will be helping systematics in general by avoiding duplication of effort and by contributing to our attempts to minimize the incompatibility of computerized systematic data or of programs generated on different projects. You will be helping yourself because not orly might you discover that someone else has already written the program, or computerized the data that you want, but also the data and programs you have created may be useful to others, thus enhancing their value.

The Register will be computerized and available for customized search requests by September 1976 . As demand warrants it, published summaries will also appear. This Register will be compatible with a similar Register for all of biology that Crovello is organizing for the American Institute of Biological Sciences.

Please address all suggestions and requests for information and for Register Questionnaires to: Theodore J. Crovello, Chairman, International Register, Department of Biology, University of Notre Dame, Notre Dame, Ind. 46556, U.S.A. 